\title{
Of Twins and Time: Scientists, Intellectual Cooperation, and the League of Nations
}

\section{Citation}

Canales, Jimena. 2012. Of twins and time: Scientists, intellectual cooperation, and the League of Nations. In Neutrality in Twentieth-Century Europe: Intersections of Science, Culture and Politics after the First World War, ed. Rebecka Lettevall, Geert Somsen, and Sven Widmalm, 243-272. New York: Routledge Press.

\section{Permanent link}

http://nrs.harvard.edu/urn-3:HUL.InstRepos:8588412

\section{Terms of Use}

This article was downloaded from Harvard University's DASH repository, and is made available under the terms and conditions applicable to Other Posted Material, as set forth at http:// nrs.harvard.edu/urn-3:HUL.InstRepos:dash.current.terms-of-use\#LAA

\section{Share Your Story}

The Harvard community has made this article openly available. Please share how this access benefits you. Submit a story.

Accessibility 


\section{Neutrality in Twentieth-Century Europe}




\section{Routledge Studies in Cultural History}

1 The Politics of Information in Early Modern Europe

Edited by Brendan Dooley and Sabrina Baron

2 The Insanity of Place/ The Place of Insanity

Essays on the History of

Psychiatry

Andrew Scull

3 Film, History, and Cultural

Citizenship

Sites of Production

Edited by Tina Mai Chen and

David S. Churchill

4 Genre and Cinema

Ireland and Transnationalism

Edited by Brian McIlroy

5 Histories of Postmodernism

Edited by Mark Bevir, Jill Hargis, and Sara Rushing

6 Africa after Modernism

Transitions in Literature, Media, and Philosophy

Michael Janis

7 Rethinking Race, Politics, and Poetics

C. L. R. James’ Critique of Modernity

Brett St Louis
8 Making British Culture

English Readers and the Scottish

Enlightenment, 1740-1830

David Allan

9 Empires and Boundaries

Rethinking Race, Class, and

Gender in Colonial Settings

Edited by Harald Fischer-Tiné

and Susanne Gehrmann

10 Tobacco in Russian History and Culture

From the Seventeenth Century to the Present

Edited by Matthew P. Romaniello

and Tricia Starks

11 History of Islam in German

Thought

From Leibniz to Nietzsche

Ian Almond

12 Israeli-Palestinian Conflict in the Francophone World

Edited by Nathalie DebrauwereMiller

13 History of Participatory Media Politics and Publics, 1750-2000 Edited by Anders Ekström Solveig Jülich, Frans Lundgren and Per Wisselgren

14 Living in the City

Urban Institutions in the Low

Countries, 1200-2010

Leo Lucassen and Wim Willems 
15 Historical Disasters in Context Science, Religion, and Politics Edited by Andrea Janku, Gerrit J. Schenk and Franz Mauelshagen

16 Migration, Ethnicity, and Mental Health

International Perspectives, 18402010

Edited by Angela McCarthy and Catharine Coleborne

17 Politics of Memory Making Slavery Visible in the Public Space

Edited by Ana Lucia Araujo

\section{Neutrality in Twentieth-Century}

\section{Europe}

Intersections of Science, Culture, and Politics after the First World War

Edited by Rebecka Lettevall, Geert Somsen, and Sven Widmalm 
Neutrality in

Twentieth-Century Europe

Intersections of Science, Culture, and

Politics after the First World War

Edited by Rebecka Lettevall,

Geert Somsen and Sven Widmalm 
First published 2012

by Routledge

711 Third Avenue, New York, NY 10017

Simultaneously published in the UK

by Routledge

2 Park Square, Milton Park, Abingdon, Oxon OX14 4RN

Routledge is an imprint of the Taylor \& Francis Group, an informa business

\section{(C) 2012 Taylor \& Francis}

The right of the editor to be identified as the author of the editorial material, and of the authors for their individual chapters, has been asserted in accordance with sections 77 and 78 of the Copyright, Designs and Patents Act 1988.

Typeset in Sabon by IBT Global.

Printed and bound in the United States of America on acid-free paper by IBT Global.

All rights reserved. No part of this book may be reprinted or reproduced or utilised in any form or by any electronic, mechanical, or other means, now known or hereafter invented, including photocopying and recording, or in any information storage or retrieval system, without permission in writing from the publishers.

Trademark Notice: Product or corporate names may be trademarks or registered trademarks, and are used only for identification and explanation without intent to infringe.

Library of Congress Cataloging-in-Publication Data

A catalog record has been requested for this book.

ISBN: 978-0-415-89377-0 (hbk)

ISBN: 978-0-203-11679-1 (ebk) 


\section{Contents}

List of Figures $\quad$ xi

Acknowledgements xiii

1 Introduction 1

REBECKA LETTEVALL, GEERT SOMSEN, AND SVEN WIDMALM

\section{PART I}

Points of Departure:

The Breakdown of Internationalism

in Science and Culture and Its Effects

2 Probing the Master Narrative of Scientific Internationalism:

Nationals and Neutrals in the 1920s

BRIGITTE SCHROEDER

\section{PART II}

International Collaborations: Neutrality in Science

3 “Holland's Calling”: Dutch Scientists'

Self-fashioning as International Mediators

GEERT SOMSEN

4 “A superior type of universal civilisation":

Science as Politics in Sweden, 1917-1926

SVEN WIDMALM

5 "Has the Swedish Academy of Sciences ... seen nothing, heard nothing, and understood nothing?" The First World War,

Biased Neutrality, and the Nobel Prizes in Science 


\section{viii Contents}

6 Pursuing Common Cultural Ideals: Niels Bohr, Neutrality, and International Scientific Collaboration during the Interwar Period 115 HENRIK KNUDSEN AND HENRY NIELSEN

7 Caught-up by Politics? The Solvay Councils on Physics and the Trials of Neutrality KENNETH BERTRAMS

8 The Scientific Construction of Swiss Neutrality DANIEL SPEICH CHASSÉ

\section{PART III}

Intellectual Positions: Neutrality and Culture

9 A Castle in the Center: The First Czechoslovak

Republic and European Cooperation (1918-1938)

CARLOS REIJNEN

10 Prague Zionism, the Czechoslovak State, and the Rise of German National Socialism: The Figure of Max Brod (1914-1933)

GAËLLE VASSOGNE

11 Legitimacy through Neutrality: Resources of Journalism in the International Press Visit to Sweden in 1923

PATRIK LUNDELL

12 Of Twins and Time: Scientists, Intellectual Cooperation, and the League of Nations

JIMENA CANALES

\section{PART IV}

Political Visions: Neutrality and Peace

13 Eye-deep in Hell: Heinrich Lammasch, the Confederation of Neutral States, and Austrian Neutrality, 1899-1920 
14 Nobel Science of Peace: Norwegian Neutrality, Internationalism, and the Nobel Peace Prize

VIDAR ENEBAKK

15 Neutrality and Humanitarianism:

Fridtjof Nansen and the Nansen Passports

REBECKA LETTEVALL

List of Contributors

Index 


\section{Figures}

1.1 Google Ngram “neutrality”. 3

1.1 H.A. Lorentz' funeral procession through Haarlem. 46

1.2 Eijkman's World Capital plan. $\quad 50$

7.11911 Solvay Council on Physics. 145

9.1 Conversations with Masaryk. 184

9.2 Beneš, Masaryk, Svehla, Benesova, and Čapek. 194

9.3 Čapek, diligent writer. 196

9.4 Friday afternoon session at Čapek's with himself in the

12.1 Einstein with members of the International Committee for Intellectual Cooperation including Marie Curie (second from left) and Hendrik Lorentz (third from left), July-August 1924.

14.1 Løvland splitting the Peace Prize in 1921 between Lange and Branting. $\quad 297$

14.2 The Norwegian Storting's Nobel Institute in 1905.

14.3 Logo from the publications of the Institute for Comparative Research in Human Culture. 305

14.4 The tree of germ plasm. 309

15.1 Fridtjof Nansen as High Commissioner of the League of
Nations, in Sofia, Bulgaria in 1922.

15.2 The Nansen Passport 327 


\section{Acknowledgements}

This book started life as a collection of papers presented at a symposium at the Nobel Museum, Stockholm, in 2008. We wish to express our deep gratitude to the Nobel Museum, to the Swedish Research Council, to Riksbankens jubileumsfond, and to Södertörn University, who sponsored the symposium. Last but not lot least we are very grateful to Charlotte Bigg who commented on the papers and gave valuable input regarding the book project as a whole. 


\title{
12 Of Twins and Time \\ Scientists, Intellectual Cooperation, and the League of Nations
}

\author{
Jimena Canales
}

In 1932, Ernst Krieck, a devout member of the National Socialist party in Germany and one of its most influential pedagogues, claimed that science was never, in the end, neutral: "In the future, one will no more adopt the fiction of an enfeebled neutrality in science than in law, economy, the State or public life generally. The method of science is indeed only a reflection of the method of government," he explained. Krieck held views which were exactly the contrary of those of the majority of scientists and intellectuals around him. Most scientists working after the First World War believed instead that science was not and should never be political and-for that very reason-that it should be neutral and international.

Krieck's views could be simply labeled anti-scientific. For Robert K. Merton, the influential sociologist of science, they represented the much wider repudiation of science (and rationality) that was extending right in front of his eyes and throughout Nazi Germany. ${ }^{1}$ But the relation of science and politics (as that of the history of science in totalitarian regimes) is more complex than either Krieck or Merton allow.

During times of intense conflict, there is often rampant disagreement about what is considered neutral versus partisan, and the dream of finding a "view from nowhere" gives way to a more modest goal of producing knowledge from a multitude of situated and partial perspectives. ${ }^{2}$ Even the notion that science is (or should be) neutral has a complicated history in itself. The historian of science Robert Proctor has traced the roots of this idea to the Socratic separation between theory and practice, arguing that it is impossible to consider science "in itself" as always and everywhere neutral. ${ }^{3}$ Furthermore, some of the most cherished values of science frequently associated with neutrality, such as "objectivity," "precision", and "impersonality" have had fluctuating relations to politics and values. ${ }^{4}$ Politics, or implications for the culture at large, simply cannot be read out from scientific theories, equations, or technologies. ${ }^{5}$

How, then, can we understand the relation of science to the ideals of neutrality which often accompanied it? Did Einstein, who considered science to be both "impersonal" and "international", hold these ideals? Science, according to him, was "a paradise beyond the personal" - a paradise which "whether you like it or not" was and would always be "international." 6 This aspect of 


\section{Jimena Canales}

Einstein's view of science fit with the broader belief, forcefully promulgated by many members of the Vienna Circle and dominating much of science and philosophy well into the last decades of the century, that in science "politics and values were to be checked at the door." ${ }^{7}$ But where, precisely, did this "door" lie? How far did debates about neutrality reach? Neutrality was not just a political ideal often held by scientists; it constituted, at their very core, some of the central scientific tenets of twentieth-century science.

To understand the complex nature of time and space in the universe, scientists-paradoxically_often turned to much simpler scenarios. Thus in 1905 in his famous theory of relativity paper, Einstein enticed the world to think about time in terms of how it was measured by clocks, and of space as it was defined by rigid measuring rods. By doing so, Einstein started a revolution in physics that had not been seen since the time of Newton, splitting the intellectual community for or against his theory. It soon became evident, however, that his apparently simple conception was much more complicated, and numerous commentators started to point out the many questions and paradoxes it entailed. The Dutch physicist Hendrik Lorentz saw that the equations he had developed before Einstein were now being used by the younger physicist and given a particular interpretation to which he was unwilling to subscribe; Henri Bergson, renowned French philosopher and the authority on the nature of time during this period, saw his life work under attack, protesting that an outdated metaphysics was once again uncritically parading as ultimate truth.

One particularly controversial aspect of Einstein's theory pertained to the time marked by two clocks rapidly moving away from each other. To understand this effect, Einstein's theory was described in even simpler terms. The physicist Paul Langevin illustrated it using an example involving only two individuals, one a voyager and another one who remained on earth. Despite Langevin's best efforts, his example was still considered not simple enough and hardly uncontroversial, so in further attempts to simplify it, others proposed to eliminate possible difficulties associated with the examples of a voyager and an earth-bound individual by thinking about it in terms of individuals of identical genetic constitution: twins. This simple fictional scenario, commonly referred to as "the twin paradox", was referred to again and again throughout the century.

Einstein, Lorentz, and Bergson-contemporaries in a world which was being torn apart by disagreements between individuals, often from different nationalities, belonging to distinct cultures, and holding different views about the significance of race and creed-referred to the paradox at the same time that they tried to mitigate the potential harmful consequences arising from these differences as members of an elite commission of the League of Nations. But reaching agreement about intellectual cooperation in the early decades of the twentieth century was as complex as reaching agreement about the nature of time in the simple fictional "twin paradox" case. Debates about the nature of the universe, the meaning of time in relativity theory, and how to best advance international causes all took 
place in the same context as discussions of a most simple case: two persons (sometimes twins) disagreeing with each other about the nature of time. With this example, scientists and philosophers hoped that politics and values could be finally left out. But by looking carefully at its history, we see (instead of a "door") a space were the categories of politics versus science are grossly inadequate, and where the most literal, denuded, and simple scenarios remain the richest, the most complex, and the most literary. ${ }^{8}$

In the late nineteenth century, the question of time intersected directly with that of neutrality in discussions about where to place the prime meridian-the degree zero of longitude-that could serve as a point of reference to all other measurements of time and longitude. A "neutral" system of longitude, argued an expert, is "a myth, a fancy, a piece of poetry", but other scientists believed that a neutral place of reference could indeed be found. The equator or the stars above the earth, argued some, were neutral enough. ${ }^{9}$

In the twentieth century, discussions of time and neutrality were more complicated, and much less evidently geopolitical than those that led to the establishment of the prime meridian at the Greenwich Royal Observatory. Scientists argued about how to account for the difference in time marked by a stationary clock and a clock in uniform motion. Should one clock, the "stationary" one, be privileged, or should scientists and philosophers remain "neutral" in assessing the differences between the two clocks and consider them interchangeable and simply in movement by reference to each other? Questions of neutrality in this context now incorporated discussions about parity, congruence, transmission, the possibilities and limits of communication, and how it related to ways of fostering or preventing agreement. Discussions no longer focused on the task of finding a neutral standpoint (either on earth or in the heavens), but rather on how (and under what conditions) it could be made possible.

\section{AN INTERNATIONAL SCIENCE}

Einstein's theory of relativity, according to many observers at the time, could not have been proved without international cooperation between scientists of different nations. The success of international cooperation in science was often exemplified with the following case: "The Theory of Einstein, the German Jew, was put to the test by British astronomers," who in 1919 led the famous eclipse expeditions that largely confirmed the theory. ${ }^{10}$ Contemporary descriptions of the "test" of Relativity Theory frequently stressed the same aspects. Einstein was almost always explicitly described as "German" and the scientists who confirmed it, "British." Thus Ernest Rutherford, one of the founders of atomic physics, explained why it was so extraordinary in precisely these terms: "an astronomical prediction by a German scientist had been confirmed by expeditions . . . by British astronomers." ${ }^{11}$ Another fellow physicist similarly explained: "The fact that a theory formulated by a 


\section{Jimena Canales}

German has been confirmed by observations on the part of Englishmen has brought the possibility of co-operation between these scientifically-minded nations much closer."12 Einstein was a two-fold hero: "Quite apart from the great scientific value of his brilliant theory, Einstein has done mankind an incalculable service", in proving the value of international cooperation..$^{13}$ During this time, the goal of advancing science and international cooperation often "blurred together." ${ }^{14}$ It was hardly a coincidence that Arthur S. Eddington, the astronomer in charge of the expeditions that largely proved the theory, was (like Einstein) a pacifist, a critic of the First World War, and an ardent defender of political and scientific internationalism.

Einstein himself frequently underlined that the confirmation of his theory came from "English astronomers and physicists" in the "proud tradition of English science" by "English scientific men" backed by "English institutions." He even argued that, given the political situation at the time of the First World War, objective judgment could only come from the English: "In Germany, for the most part, a newspaper's political orientation dictated its judgment of my theory; the attitude of English scientists, on the other hand demonstrated that their sense of objectivity is not clouded by a political point of view." 15

The importance of these national associations in the context of science seemed at times paradoxical or even humorous. Einstein explicitly referred to the complex connotations that his newfound fame brought on by reference to his complicated German, Swiss, and Jewish background:

By an application of the theory of relativity [ . . ], to-day in Germany I am called a German man of science, and in England I am represented a Swiss Jew. If I come to be represented as a bête noir, the description will be reversed, and I shall become a Swiss Jew for the Germans and a German man of science for the English. ${ }^{16}$

The astrophysicist Willem Julius, who looked for additional proofs for Einstein's theory, but was failing to find any, mockingly claimed that the sun was not cooperating as well with "the British Empire", as it had previously done during the eclipse expeditions. The evidence he found was unfortunately "even less likely as a consequences of a repulsive force that the Earth specifically, or the British Empire, were exerting upon the solar gases." ${ }^{17}$ Although he always noted and was thankful for the particular role played by the British scientists, Einstein always firmly believed that behind these complex politics lay a "purely objective matter." 18 But others disagreed.

\section{BEYOND “EINSTEIN ON POLITICS”}

Einstein's involvement with politics started with his pacifist stance during the First World War and his participation in the New Fatherland 
Association. Einstein began to actively support international collaborations in science after the First World War. During these years he started publicly insisting that internationalism and science went hand-in-hand because "scientific creations [...] elevate the human spirit above personal and selfish nationalistic aims." 19 Scientists, according to Einstein, had to play a singular role in promoting international relations: "Scientists $[\ldots]$ must be pioneers in this work of restoring internationalism." ${ }^{20}$ Internationalism was a prerequisite "for pure objectivity to prevail." In support of this idea, he cited a comment by his colleague Emil Fischer: "Whether you like it or not, gentlemen, science is and always will be international." 21

After his 1919 launch to stardom, much of his (and his new wife's) energy was directed toward a cultural Zionist cause, advocating unrestricted Jewish immigration or "large-scale Jewish colonization" of Palestine along with the creation of a university in Jerusalem. ${ }^{22}$ In the spring of 1920 he started offering accredited university courses to Jewish students who were unable to register at German universities because of quota limits. During that summer, he was vigorously attacked in a series of anti-relativity lectures at the Berlin Philharmonic Hall, marking the beginning of painful anti-Semitic tirades against him. ${ }^{23}$

After those attacks, Einstein increasingly claimed that anyone who opposed his theories did it for political reasons. ${ }^{24}$ By 1921 he publicly stated that he did not consider the possibility of any legitimate critique: "No man of culture, of knowledge, has any animosity toward my theories. Even the physicists opposed to the theory are animated by political motives." 25 When asked to elaborate about political motives, Einstein referred to anti-Semitism.

Einstein was hardly alone in his political involvement as a scientist. He was part of a generation of many prominent scientists who were also politically engaged and very influential outside of scientific forums. His own engagement with politics spanned almost half a century marked by two world wars and covering topics ranging from the use of nuclear weapons to the civil rights movement in the United States. ${ }^{26}$ But a focus on Einstein's political involvement (already the topic of numerous books and essays) can miss aspects of his work that cannot be easily classed as either political or scientific. Einstein's interpretation of the twin paradox, and his dissent from the interpretation advanced by two of his contemporaries, the Dutch physicist Hendrik Lorentz and French philosopher Henri Bergson, falls in this nether land.

\section{THE “TWIN PARADOX”}

In 1911 Einstein's theory of relativity gained a renewed interest for physicists, philosophers, and the general public in a new formulation proposed by Paul Langevin. ${ }^{27}$ In a congress for philosophers in Bologna, in which Bergson was the undisputable star, Langevin discussed a paradox that was subsequently named the "twin paradox". Langevin's original publication 


\section{Jimena Canales}

did not talk about twins, or use the common names later given to the twins of Peter and Paul, but simply described a single "voyager" taking off from earth in an imaginary rocket. Yet eventually, the paradox obtained a standard form that has been repeated over and over.

The common formulation of the paradox can be summarized as follows. According to the theory of relativity, two twins (one who traveled in outer space at speeds close to the speed of light, and another one who remained on earth) would come back together to find that time had slowed down for the twin who had traveled. The twin who stayed on earth would have aged more rapidly; the traveling twin would be younger. Their clocks and calendars would show disagreeing dates and times. Although initially formulated as a "thought experiment", many scientists claimed that various effects described and predicted by Einstein's theory showed that the paradox would indeed take place. A stunning "confirmation" took place in 1972 when scientists tested their theory by transporting an atomic clock eastward around the world and comparing it with one transported westward. To their amazement, they found that the far-east traveler lost 59 nanoseconds, while the one transported westward gained 273 nanoseconds. ${ }^{28}$

The paradox took time to reach its traditional, often-repeated form. At first its full implications escaped even Einstein, who in 1905 (when he first formulated the theory of relativity), did not even see a paradox. Einstein later believed that "the thing is at its funniest" when it was considered in terms of its effects on "organisms," starting to ask if the dilation of time as marked by a clock would also affect biological—and not only physical-processes. ${ }^{29}$ Soon thereafter Einstein started to consider time dilation as much more than the delay of particular clocks, claiming that relativity affected "the temporal course of no matter which process." 30

The "twin paradox" became particularly important for Einstein and his interlocutors because it aptly illustrated aspects of his interpretation of relativity theory that differentiated his position (and his particular contribution) from others'. It was an important example for Einstein's particular interpretation of relativity theory by separating it from the contributions of Henri Poincaré and Lorentz, two of his contemporaries, and which was used to demonstrate the relevance of some of his most arcane claims for the common understanding of time in general.

Years before Einstein, both Poincaré and Lorentz had already worked on a theory that was very close to Einstein's yet differed in essential ways. First, Lorentz developed the famous equations later used by Einstein. Then, in 1900, Poincaré brought Lorentz's research to a different level by giving a physical interpretation of the equations in terms of the slowing down of clocks. ${ }^{31}$ Yet there was something essential and unique about Einstein's work that was not present or foreseen by the others: Einstein's particular interpretation of the notion of time. His interpretation of the "twin paradox" exemplified this particular interpretation. 
His main difference with Lorentz and Poincaré, and the reason for which Einstein eventually received credit for revolutionizing physics, was that neither of the other two men thought that these relativity effects should revolutionize physics. Neither of them thought that concepts of time and space should be overhauled. Neither man thought that these variations in time and length should be considered "real" in the same terms that Einstein did.

Lorentz and Poincaré both realized that in cases where clocks moved at high velocities the time shown by the fast-moving clock would be delayed vis-à-vis the slow-moving clock. They both used the same formula to calculate the exact amount of each clock's delay as it varied according to its speed. The famous formula related a time variable (usually written as $t_{2}$ ) in terms of another time value (usually written as $\left.t_{1}\right): t_{2}=t_{1}\left[1 /\left(1-v^{2} / c^{2}\right)^{1 / 2}\right.$. But Einstein differed with Lorentz and Poincare about the meaning they gave to $t_{1}$ and $t_{2}$ and how these variables related to our notion of time in general.

Einstein at first considered the theory of relativity to belong equally to Lorentz. In 1906 he referred to relativity as "the theory of Lorentz and Einstein." 32 Lorentz called one of the changed magnitudes "local time" (and in the similar length equations he called it "apparent length"), but Einstein eventually came to believe that there was nothing unique, let alone "local" or "apparent" about it. He increasingly separated himself from Lorentz's position, starting in 1907, when he referred separately to "the H.A. Lorentz theory and the principle of relativity." 33 Einstein stated his difference with Lorentz clearly and in detail, claiming that he understood Lorentz's "local time" as time in general: "Surprisingly, however, it turned out that a sufficiently sharpened conception of time was all that was needed to overcome the difficulty discussed." 34 Einstein's new interpretation of time and his difference with Lorentz's was supported by Hermann Minkowski in a famous September 1908 lecture. It would soon become the main mark of Einstein's priority.

What is more interesting is Einstein's next claim: that his redefinition of "local time" as "time" in general was right, and that Lorentz's was wrong. Although in his famous 1905 publication Einstein already explained that he was talking about "time", his claim was initially much more modest. Then, it was closely associated with clock time, and did not even include all clocks. He was careful to say that his theory applied mostly to a "balancewheel clock" and in later editions he added a footnote saying it would "not" apply to "a pendulum clock, which is physically a system to which the Earth belongs. This case had to be excluded." ${ }^{35}$ Even after he expanded the importance of relativity beyond clock time, Einstein initially did not claim that his theory was the only explanation of the observed effects, but that it was one possible explanation among many others. He did however insist that it was the better one, because in contrast to Lorentz's, (he argued) it was not ad hoc or artificial. ${ }^{36}$ 
By October 1909 Lorentz was ready to concede that Einstein should "take credit" for "the manifestation of a general and fundamental principle" of relativity-something he had not done. But in that same Göttingen lecture, Lorentz also said that "Einstein simply postulates what we have deduced, with some difficulty and not altogether satisfactorily." And that Einstein's formulas were "rather complicated and look somewhat artificial." 37 While Einstein framed Lorentz's theory as artificial-looking, Lorentz framed Einstein's in the same way. In his 1910 lectures Lorentz used the term "Einstein's Relativitätsprinzip", clearly attributing it to Einstein. ${ }^{38}$ Lorentz's clear acknowledgement of Einstein's credit was hardly an endorsement. Einstein (and Minkowski), Lorentz argued, denied the existence of one true universal time. He wanted to keep it.

In 1914, in a book titled Das Relativitätsprinzip collecting some of the most important documents on the relativity theory by various authors, Lorentz's contribution showed clear disagreements with Einstein: "Einstein says, in short, that all the questions just mentioned have no meaning." The crux of their difference resided in the exceptional importance Lorentz gave to epistemology (specifically, in relativity theory and more generally, in science): "The evaluation of these concepts (relativity, time) belong mainly within epistemology, and the verdict can also be left to this field". For Lorentz epistemology was central to the meaning of the theory. ${ }^{39}$

Einstein became even clearer about his difference with Lorentz in an article published for a general audience in a multivolume "Encyclopedia of the Present" commissioned to promote Germany. The article included a clear criticism of Lorentz's interpretation. ${ }^{40}$ After reading the article, Lorentz complained about it in a private letter to Einstein: "In your article of the Kultur der Gegenwart I find in the discussion [ . . ] the remark: 'This manner of thinking up ad hoc hypotheses to cope with experiments $[\ldots]$ is very unsatisfactory" , noticing that it referred directly to him. ${ }^{41} \mathrm{He}$ strongly chastised Einstein for "presenting a personal view as self-evident" in his claim that there could be no distinguishing factor for preferring one time over the other. Lorentz then proceeded to describe all that was wrong with Einstein's interpretation, settling largely on two main points.

The first issue had to do with the equivalence of time and space. Space and time were not simply interchangeable: "an unmistakable difference exists between spatial and temporal concepts, a difference which you also certainly cannot remove entirely. You cannot view the time coordinates as totally equal in status with the space coordinates." The second issue had to do with the equivalency of the status of the different times. Lorentz was ready to concede that imperfect spirits could not give more importance to one time over the other, but a "universal spirit" would. But, what is more, Lorentz argued that we, humble human beings, were nonetheless similar to this "spirit": "surely we are not so vastly different to it," he argued. The idea of a universal spirit's conception of time had a long history going back to medieval times and still appearing forcefully in Newton's work. To Lorentz the question of a "universal spirit" and 
the ability to disentangle the equivalency of the status of $t_{1}$ and $t_{2}$ went "beyond the bounds of physics." 42

By January 1915 it was clear that Lorentz and Einstein disagreed in their interpretation of relativity theory; they disagreed about the status of $t_{1}$ and $t_{2}$ vis-à-vis time in general; they disagreed about what they felt constituted the "bounds of physics"; they disagreed about the role of "epistemology" in science; they disagreed about what was "artificial" in scientific hypotheses; they disagreed about what should be considered as a "personal view" instead of being "self-evident." Lorentz considered Einstein's theory of relativity as one of many other possible options. Yes, special and general relativity were correct: "I do not mention that, also in my opinion, not only the theory of relativity but also your gravitation theory can remain valid in their entirety." But they were not the only way to see things: "They will just not impose themselves on us so much as the only possible ones." ${ }^{3}$

Lorentz and Einstein nonetheless agreed about many other things and deeply admired each other as individuals. They became increasingly aligned in their opposition to the First World War and in their defense of "international" cooperation. In 1919 Lorentz was among the first physicists who contributed to bringing Einstein's theory to the wider public. His short, popular book The Einstein Theory of Relativity called it "a monument of science" and extolled the "indefatigable exertions and perseverance" of the man. ${ }^{44}$

In the 1920s Lorentz continued to support Einstein as an individual, despite their differences. His support peaked after Einstein suffered antiSemitic attacks at the Philharmonic Hall. Nonetheless differences remained. In 1922 he still insisted that "one may, in all modesty, call true time the time measured by clocks which are fixed [ . . ] and consider simultaneity as a primary concept." 45

\section{ENTER BERGSON}

Disagreement about the meaning of $t_{1}, t_{2}$, and time in general became a much wider problem after Bergson published his controversial Duration and Simultaneity. The book recounted in detail the famous "twin paradox," and interpreted it in a manner that differed sharply from Einstein's. Einstein and Bergson had met months before on 6 April 1922 when the book had not yet appeared but was already in press, in a widely publicized meeting in Paris widely considered "a sensation that the intellectual snobbery of the capital could not pass up." 46

Bergson at that time was an established figure both as a public intellectual and philosopher, hobnobbing in the morning with heads of state, filling lecture rooms in the afternoon, and providing bedtime reading for many at night; Einstein was only then a rising star in science and starting to find his voice outside of scientific circles.

The two men largely dominated the intellectual landscape of the first half of the twentieth century, representing two competing sides of modern 


\section{Jimena Canales}

times. Bergson's work became associated with metaphysics, anti-rationalism, and vitalism (the idea that life permeates everything). Einstein's with their opposites: with physics, rationality, and the idea that the universe (and our knowledge of it) could fare just as well without us. Both men were envied by many of their contemporaries. Even Sigmund Freud once described himself as having "little claim to be named besides Bergson and Einstein as one of the intellectual sovereigns" of his era. ${ }^{47}$ The debate between Bergson and Einstein was described as "a controversy that presently separates the two most renowned men of our times." 48

Einstein's visit was highly symbolic for the two countries, coming at a time of extreme tension between France and Germany. ${ }^{49}$ A German ultranationalist opponent of Einstein complained that this was simply "not the proper time", for Einstein to go to France:

Since the end of the war the French have suppressed the German people in the most brutal manner. They have torn away piece after piece of their body, have engaged in one act of extortions after another, they have placed colored troops to watch over the Rhineland, and they have made insufferable demands on the German people through the reparation commission. And just at this very time Mr. Einstein travels to Paris to deliver lectures. ${ }^{50}$

Others held exactly the opposite view, optimistically believing that it would help reduce the strain between the two countries. Einstein was invited with the express purpose that his visit would "serve to restore relations between German and French scholars." He quoted the letter of invitation from Langevin in his travel notification to the Prussian Academy of Sciences: "The interests of science demand that relations between German scientists and us be reestablished." Langevin argued that Einstein "will contribute to this better than anyone else." 51

After receiving three invitations (the last one from the Collège de France), Einstein declined all of them. He had second thoughts, however, about the last one. These doubts intensified after a conversation with the Foreign Minister (and amateur science-fiction writer) Walther Rathenau who worked to improve relations between these two countries, and who urged him to attend. ${ }^{52}$ Shortly thereafter Einstein withdrew his declination, notified the Prussian Academy of Sciences, and prepared his trip. ${ }^{53}$ Political tensions only escalated when Einstein returned, and Rathenau, who had been responsible for convincing him to go to Paris, was assassinated.

\section{"WE SHALL HAVE TO FIND ANOTHER WAY OF NOT AGING."}

Bergson's Duration of Simultaneity set off a chain reaction of responses from various scientists and intellectuals who took sides for or against. The 
debate was particularly shocking because many of those involved believed that the two men should reach some sort of agreement. Intellectuals were all well accustomed to "endless discussion without resolution over the best structure to give a government, or over the most perfect form of art, or over a certain problem of metaphysics or ethics", but this should not happen in a case "dealing only with logical deductions based on facts that none of the adversaries even dream of contesting." 54 This was a "disconcerting thing, and perhaps, without precedent." 55 There needed to be an end to something that could only be explained as "a colossal misunderstanding" or a "monstrous mistake." Something radical had to happen in order to have "everyone to agree." 56

Readers often cite a particular sentence in Duration and Simultaneity where Bergson wrote about the twin paradox. Bergson claimed that "once re-entering [Earth], it [the clock of one of the twins] marks the same time as the others." 57 This single statement about clocks discredited him in the eyes of most scientists. Many claimed that Bergson "was not sufficiently conversant with the outlook and problems of mathematics and physics." 58 Since then, most readers insist that Bergson denied the fact that the times of the twins would differ.

Bergson responded to some critics in a second 1923 edition of his book, where he included three new appendices. But even in the second edition, Bergson categorically stated that the traveling clock "does not present a delay when it finds the real clock, upon its return." ${ }^{59}$ In the preface, he claimed to "explicitly prove that there is no reference, in what concerns Time, between a system in motion and a system in uniform translation."

Bergson, in the years that followed, focused even more intently on the implications of having the twin's clock times differ. This correction was most clearly stated two years after his first encounter with Einstein in "Les Temps fictifs et les temps réel" (May 1924). There he insisted that even if the twin's clocks differed, his major philosophical point still held. What was this point? Although complex, one aspect of it remained clearly tied to his interpretation of the twin paradox.

So how did Bergson differ with Einstein? When Bergson entered into the fray in 1922 he first insisted that one of the twin's time was "real" while the other's was "fictional." His philosophical project consisted in determining how these boundaries-between the real and the fictional-were established more generally. When he admitted that the times would differ, he still insisted that the discrepancy between the twins' times did not necessarily imply that they should both be unequivocally considered in equal terms. So what if one of the twins' clocks showed a different time than the other's? One did not have to comply with Einstein's particular answer, argued Bergson.

Differences in clock times proved that something in one of the twins' scenarios was different from the other's. Their experiences of time were thus not entirely equal. Which of the twins' clocks' time was correct? For 


\section{Jimena Canales}

Einstein, both were equally correct. Physics, his physics, showed that. Bergson disagreed. When the twins met back on earth, and compared their differing clocks it was not immediately clear to him which of these times would be taken as correct. Although physically they could arguably have equal privileges, philosophically differences would remain between the two twins. Whose time would prevail back on earth would depend on how their disagreement was negotiated-psychologically, socially, politically, and philosophically. Mockingly comparing the sensational conclusions of Einstein's interpretation of relativity to the fantastical searches for the fountain of youth, Bergson concluded: "We shall have to find another way of not aging."

Bergson at first focused on differences in the twins' experiences of effort and memory, and then (after criticisms were launched at him claiming that he did not understand Einstein's science) he focused on acceleration, a clear physical difference. He argued that acceleration was the essential difference that produced a difference in times. Acceleration created a dissymmetry, which in turn proved that the twins' times were not equal in every sense

So, if one wants to deal with Real Times then acceleration should not create a dissymmetry, and if one wants for the acceleration of one of these two systems to effectively create a dissymmetry between them, then we are no longer dealing with Real Times. ${ }^{60}$

Acceleration was an inescapable mark of a difference in the twins' travel itineraries. Since a difference existed, one that resulted in a difference in times, then their times were not equal in every respect.

Einstein insisted that the issues that so fascinated Bergson were irrelevant for physics. Both twins experienced "Real Times"-equally real-according to Einstein. In addition, on many occasions Einstein and a number of his defenders claimed that the differences in times appeared even if there was no acceleration. The twin paradox should hold even under the special theory (that did not account for acceleration effects) alone. To prove this, they devised new scenarios. One of the most popular involved the introduction of a third twin, usually called the triplet, who would accelerate to compare her clock against that of the un-accelerated travelling twin and attest to the time difference. Or they had the two twins exchange time signals every step of the journey. Or they laced the path of each twin with coordinated clocks. These new scenarios solved some problems, but opened others. The plot thickened and the debate intensified.

The philosopher André Lalande, one of the founders of the Société française de philosophie, considered Bergson's arguments as a whole and across all of his publications. Unlike most of those who followed the debate between the two men, he did not limit himself to citing the usual out-of-context quotes. Unlike most other readers, he understood that Bergson did eventually acknowledge that the times would differ. He 
also understood that even then the disagreement between the two men remained, which he summarized as follows: "The chief question here, of course, is to know what sort of reality should be accorded to the various opposed observers who disagree in their measurement of time." ${ }^{61}$ Another follower of the debate drew a similar conclusion: "Bergson admits all of the results of relativity, but only refuses to accord them the same real value." 62 Many other commentators accepted Einstein's theory and its consequences, but were similarly loathe to ascribe an equal reality to the different times of the theory. An author of a book on relativity simply said that Einstein treated the "discord between clocks as real." But that it would "no doubt" be better to qualify this by saying that these cases should be treated "as if" they were real. ${ }^{63}$

The question of how reality was bestowed to certain things and not to others was indeed at the crux of Bergson's philosophy. For Bergson, the line between reality and fiction was fraught. For Einstein, it was not.

\section{FIGHTING TWINS}

A sufficiently uncooperative twin could still claim that only his clock showed the real time. The role of power and will to dominate could not be kept out of interpretations of the twin paradox. Even in 1911, at the very moment when the paradox was first introduced, the perspicacious philosopher Léon Brunschvicg underlined the issue of "domination" when he remarked that physicists should not forget that every "observer" described in the relativity theory was potentially "also a maker of clocks," and could potentially "want to dominate the diverse groups of observers, incapable of bringing the clocks into agreement, instead of being confused among them." ${ }^{\circ 4}$ What would a dominant twin do?

Eddington, who also understood Einstein's theory as one that assigned equal reality to the different times measured by different observers, described Einstein's position in clearly value-laden terms. He considered Einstein's interpretation of relativity as a fairer position than alternative ones, all of which he understood in juridical, political (and even slightly comical) terms. Einstein's theory was radically democratizing, and it was also a way to avoid conflict through the reconciliation of conflicting points of view. When discussing the question of what was the difference between a stationary observer (a twin that stayed on Earth) and a moving one (the one who travelled), Eddington used the example of a falling "drunken man who explained that "the paving-stone got up and hit him"” and who "dismiss[ed] the policeman's account of the incident." According to Eddington, the story in which "the paving-stone overtook him and came in contact with his head" should be validated. Both his and the policeman's account were true: “Einstein's position is that whilst this is a perfectly legitimate way of looking at the incident, the more usual 


\section{Jimena Canales}

account given by the policeman is also legitimate." Einstein "endeavors like a good magistrate to reconcile them both." 65 To think otherwise was terribly "ego-centric" since "Nature provides no indication that one of these frames is to be preferred to the others." 66

Disagreements among the twins were frequently considered in the same way as more pressing and present forms of disagreements, such as those currently facing nations and, within them, scientists. Scientists often worked in both of these contexts. Only five days before he met Einstein in Paris, Bergson was voted unanimously to become the president of the International Committee for Intellectual Cooperation (ICIC) of the League of Nations. Einstein would join as a member.

The ICIC was founded on the hope that if intellectuals could learn to cooperate then nations might follow. It initiated a wide range of activities, pertaining to elementary and secondary education, the creation of bibliographic databases, faculty and student exchanges, intellectual property, nomenclature, scientific organization, dissemination, and access to knowledge, among others. The leadership of Bergson was essential, since he was one of the most politically committed intellectuals of his time. Einstein's participation in the Committee was also important. Bergson needed him, since he was well aware that the power of the ICIC depended on the prestige and strength of its members. Knowing that the ICIC "will only succeed, will only impose itself by the prestige and the authority of its members", Bergson worked hard to include Einstein. ${ }^{67}$ But disagreements between the two men plagued the Committee, which finally failed in 1939 in the face of imminent war.

After the First World War, German scientists were often excluded from international scientific and academic forums (such as the Solvay Congresses), just as German nationals were excluded from many governmental forums (such as the League of Nations). ${ }^{68}$ At the start of the First World War, Bergson, who was then president of the Académie des sciences morales et politiques, was pressured by a group of members of the Institut de France who demanded the expulsion of foreign associates of German nationality. ${ }^{69}$ The philosophers of the Institut, as a group, condemned this initiative. Bergson, during his tenure as president, drafted a declaration that condemned the war but did not go to the extreme of expelling German nationals. ${ }^{70}$ These politics of exclusion affected Einstein's Paris visit. In 1922 the Académie des sciences refused to allow him to lecture on the grounds that Germany did not belong to the League of Nations. A critical newspaper questioned their logic: "If a German were to discover a remedy for cancer or tuberculosis, would these thirty academicians have to wait for the application of the remedy until Germany joined the League?" 71

A few days after his meeting with Bergson, the two men were supposed to meet again in Geneva at the inaugural meeting of the ICIC. Einstein missed its first meeting (1-5 August 1922). He then thought of resigning because of the prevailing anti-German sentiments of many of its members. ${ }^{72} \mathrm{He}$ did 
not feel he could adequately represent Germany because of his "condition as Israeli, on the one hand, and on the other because of his anti-chauvinistic feelings from the German point of view do not permit him to truly represent the intellectual milieu and the Universities of Germany." ${ }^{73}$ Nonetheless, Einstein was invited as a representative of German science. Einstein was in a difficult position; Marie Curie and others pleaded with him, and he chose to remain.

By the second meeting he had resigned in earnest (March 1923), publishing a sharply worded statement against the ICIC. ${ }^{74}$ Einstein protested that the League of Nations had watched helplessly as the French, refusing to send the problem of Germany's war-reparations to arbitration, occupied the German Ruhr region. The government of Raymond Poincaré, Henri Poincaré cousin, had sent the troops to the Ruhr industrial area to seize control of production. "The League of Nations", argued Einstein, "fails not only to embody the ideal of an international organization, but actually discredits it." 75 His highly public resignation only made the work of the League of Nations and the ICIC more difficult. His behavior appeared paradoxical to many of his colleagues. ${ }^{76}$ How could a scientist who preached about internationalism refuse to take place in these outreach activities? After all, he was being invited (they had indeed pleaded) as a German-born member. Had not Einstein repeatedly protested the exclusion of German scientists?

His colleague Max Born wrote to him after hearing the news of Einstein's resignation. Could it be true?

The papers report that you have turned your back on the League of Nations. I would like to know if this is true. It is, indeed, almost impossible to arrive at any rational opinion about political matters, as the truth is systematically being distorted during wartime. ${ }^{77}$

During this tumultuous period Einstein considered his theory of relativity in ways that can neither be considered exclusively in political or scientific terms. In a letter to his friend Maurice Solovine, he connected his decision to resign directly to Bergson's reception of relativity:

I resigned from a commission of the League of Nations, for I no longer have any confidence in this institution. That provoked some animosity, but I am glad that I did it. One must shy away from deceptive undertakings, even when they bear a high-sounding name. Bergson, on his book on the theory of relativity, made some serious blunders; may God forgive him. ${ }^{78}$

Forced to explain his decision to resign from the ICIC and to combat views that he was being pro-German, he stated that his position was consistent with the theory of relativity. In a letter to Marie Curie, he explained: "Do not think for a moment that I consider my own fellow countrymen 
superior and that I misunderstand the others-that would scarcely be consistent with the Theory of Relativity." 79 Relativity, in those years, went beyond his famous Annalen der Physik papers.

Although Einstein had repeatedly protested the exclusion of German scientists from international forums, in 1923 he boycotted them despite being invited. He explained to Marie Curie: "I have requested, furthermore, that I not be invited to Brussels [to attend the Solvay Congress]." ${ }^{80}$ Einstein's claims that they were excluding Germans provoked Lorentz to write a letter (on 15 September 1923) explaining to Einstein that it was not true that German scientists were excluded on principle. But Einstein had lost hope in the League. In a private letter sent to his close friend Michele Besso, he explained how he felt "proud not to have been duped by the League of Nations." That would have been a complete "waste of time and energy", due to the complete "hypocrisy" of the institution. ${ }^{81}$

\section{COFFEE BREAK}

On 6 March 1924 crisis hit the ICIC. Gilbert Murray, scholar of ancient Greek literature, world peace advocate, and vice-president of the organization, sent a letter to the Times accusing the Committee of being anti-German. The ICIC responded by publishing numerous invitations of German scientists and institutions and evidence of how they, German scientists, had turned down these invitations. Bergson, who could not disguise his anger towards Murray, needed Einstein more than ever. ${ }^{82}$ When asked how they should best respond to the crisis and to the accusations, Bergson responded: "It would be extremely useful if Prof. Einstein joined the Committee again." $\$ 3$

All of this happened at the very moment that the debate between the theory of relativity and Bergson's philosophy was reopened in the July 1924 issue of the Revue de philosophie. The equality of the different times in the twin paradox was again discussed. Meanwhile, the position of France was being weakened because of its widely rejected occupation of the Ruhr area and the concurrent devaluation of the franc. The British thought that they could profit from this situation. Murray asked Einstein if he would join, and he accepted. ${ }^{84}$

The philosopher Isaac Benrubi, amongst others, decided to attend the ICIC's meeting in Geneva (25 July 1924) only after learning that both Einstein and Bergson would attend ${ }^{85}$ The fate of the Committee was now colored by the infighting between Bergson and Einstein. For its participants, the Einstein-Bergson debate was at least as important as the Committee's meetings.

For the meeting proper Bergson reintroduced Einstein with a flattering eulogy, but during the meeting break their differences once again became evident. Benrubi, who attended the conference because of Einstein's and Bergson's presence, precipitated himself towards Einstein to ask him what 


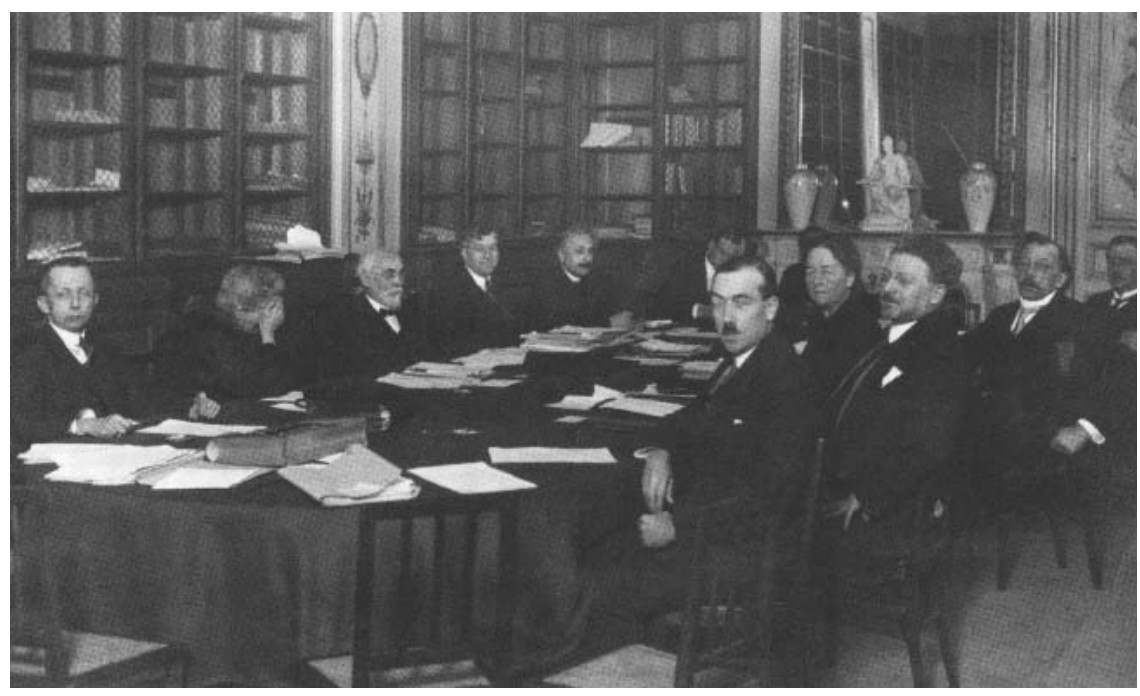

Figure 12.1 Einstein with members of the International Committee for Intellectual Cooperation, including Marie Curie (second from left) and Hendrik Lorentz (third from left), July-August 1924. Source: UNOG Library, League of Nations Archives.

he thought of Duration and Simultaneity. Einstein offered his official response, that Bergson had not understood the physics of relativity, that he had made a mistake. ${ }^{86}$ Asked if he would continue the fight against Bergson, Einstein responded: "No, I do not intend to do that, unless Bergson himself provokes a polemic. But that would not help anybody." Einstein was willing to let bygones be bygones: "New grass will grow, and then one will be able to judge with more objectivity." ${ }^{87}$ Reporting to the Frankfurter Zeitung right after the meeting, Einstein nonetheless expressed discontent about the role of the French during the meeting, which was, of course, led and chaired by Bergson as president: "It is true that the French mentality may unwittingly have dominated the proceedings to some extent". ${ }^{88} \mathrm{On}$ numerous occasions Einstein lamented the "impression of French predominance", at the ICIC, especially since "the chairman of the committee has so far also been a Frenchman". ${ }^{89}$

Bergson and Lorentz continued to think about Einstein's theory of relativity in relation to reaching agreement on the meaning of the two clocks of the twin paradox, at the same time that they thought about the best way to advance the goals of the Committee. The two men became close after Einstein resigned from the ICIC and was replaced by Lorentz. On 28 November 1924 Bergson sent a letter inviting Lorentz over to dinner that included the following promise: "We will be absolutely alone." That same letter thanked Lorentz for having sent Bergson a note on "the two clocks": "My first impression", wrote Bergson, "is that your argument is irreproachable". 
He then added a key line that told how their arguments were almost the same: "and for that reason mine remains correct [juste]." 90

Einstein and Bergson did not learn to work together at the ICIC. Passions again flared when the French government offered the ICIC the option of building an International Institute for Intellectual Cooperation (IIIC) in Paris. Einstein (and others) expressed his concern that the ICIC was international only nominally, and in effect nationalistically French. But Bergson thought he should not turn down the government's generous offer. When Bergson accepted, Einstein became more and more suspicious of the ICIC's underhand nationalism. He did not attend the next meeting, which was held in Paris instead of in Geneva. ${ }^{91}$ Bergson, in turn, did not support Einstein's Zionist causes. When Einstein invited Bergson to participate in the inauguration of the Jerusalem University, Bergson declined politely (in February 1925) saying he was too busy. ${ }^{92}$

In 1925 Bergson resigned, citing an illness. ${ }^{93}$ This resignation marked the end of Bergson's political involvement. After that date he completely retired from public life. Lorentz assumed the presidency-the second leader of the ICIC who held a view of time that could not be reconciled with Einstein's.

Einstein did not increase his attendance. During the meeting of 28 July 1925, Einstein decided to write to Besso a letter on his recent work on a unified theory, explaining to his friend: "This letter was written during a boring meeting of the League of Nations." ${ }^{94}$ Later he described the ICIC as a "keen disappointment" and a "weak and imperfect instrument" that has "by no means fulfilled all the expectations which accompanied its founding." 95 He supported the League only au faute de mieux.

In 1928, prompted by new experimental results, Lorentz again stated his position on relativity theory, giving Einstein full credit for it. While he had introduced the concept of local time, he had

never thought that this had anything to do with the real time. The real time for me was still represented by the old classical notion of an absolute time, which is independent of any reference to special frames of co-ordinates. There existed for me only this one true time. ${ }^{96}$

Einstein could take full responsibility:

So the theory of relativity is really solely Einstein's work. And there can be no doubt that he would have conceived it even if the work of all his predecessors in the theory of this field had not been done at all. His work is in this respect independent of the previous theories. ${ }^{97}$

He granted Einstein a lot: “To the experimental evidence which we already had, the charm of a beautiful and self-consistent theory was then added." "No Nonetheless Lorentz continued to believe in his interpretation: "Asked if I consider [my interpretation] [ . . . ] a real one, I should answer 
'yes.' It is as real as anything we observe." 99 And he continued to believe that Einstein "simply postulated" his own theory. ${ }^{100}$

By 1929 Einstein still deeply believed that the domination of the Institute by the French was "a fact which is not conducive [ . . . ] to international solidarity." 101 To the mathematician Jacques Hadamard he described the League as "impotent." 102 He told the New York Times that he had been "rarely enthusiastic about what the League of Nations has done or has not done." ${ }^{103}$ From 1926-1930 Einstein attended only three meetings. ${ }^{104} \mathrm{He}$ explained to the scientist and politician Paul Painlevé that "I have always regretted the fact that the institute was established in Paris and financed exclusively by French funds." ${ }^{05} \mathrm{He}$ argued "to move the institute in toto to Geneva and have all countries contribute to its financial support under a quota system." ${ }^{106}$ In July 1930 he again criticized the Committee, and resigned for the second time. Murray wrote about the woes that replacing Einstein imposed on the institution, and pointed his finger to a quick fix: "The best solution of all these difficulties is obvious! It is that you should remain with us, but perhaps that is too much to hope for." ${ }^{107}$

Einstein decided to participate once again in the Solvay Congresses, which started to be dominated by an alternative physical theory: quantum mechanics. At the Solvay Congress of 1927, Einstein "expressed [... ] a deep concern" over physicists' disagreement about causality in physics, uttering his famous argument that God did not play dice with the universe. ${ }^{108}$ At the following meeting physicists could not yet come to agreement amongst themselves about fundamental aspects of physics. Einstein locked horns with Niels Bohr on topics which would be debated in later years. The disagreement at the meeting profoundly affected Einstein, who "expressed a feeling of disquietude as regards the apparent lack of firmly laid out principles for the explanation of nature, in which all could agree." 109

Bohr described how the Solvay Congresses "took quite a dramatic turn" after they became plagued by important disagreements pertaining to the relation between the theory of relativity and quantum mechanics. ${ }^{110}$ Some prominent advocates of quantum mechanics, such as Louis de Broglie, saw Bergson's philosophy as revindicated by the new science. At the time of Bergson's death in 1941 the literary critic André Rousseaux insisted that it was not Bergson who had been wrong on science, it was the science that had been wrong. Bergson had been wrong merely when judged by the "science of his time" which was one that "was soon being marked by caducity." 111

The Nazis rose to power early in 1933. The physicists continued to disagree, but meeting together became increasingly hard. Einstein was unable to attend the Solvay Congress of 1933 . What was worse, their discussions during those years seemed to many unfit for scientists, but international reunions were unable to muster consensus. In 1936, the Second International Congress for the Unity of Science was another display of disunity.

In 1938 the ICIC held it necessary to forge consensus in the physical sciences (mainly on the Quantum-Relativity debate), while still under the 


\section{Jimena Canales}

auspices of the League of Nations. ${ }^{112}$ "These aspects of the situation were especially discussed at a meeting in Warsaw in 1938, arranged by the International Institute of Intellectual Co-operation of the League of Nations," recalled Bohr. ${ }^{113}$ But the ICIC's efforts failed, and did not produce one of its much hoped for result: agreement, either political, or scientific, or of any other kind. One year later, the ICIC lost so much momentum that it had its last meeting on July. ${ }^{114}$

Einstein completely and publicly abandoned his pacifist stance. Hoping that another institution "differing from the present League of Nations in Geneva, would have at its disposal the means for enforcing its decisions," he started to advocate an international standing army and police force. ${ }^{115}$ In August 1939 he sent a letter to President Roosevelt urging nuclear weapons research.

\section{TWINS RETURN}

Late in his life, Einstein was asked to write an article for the Library of Living Philosophers which he jokingly described as an "obituary." It was filled by articles about Einstein that touched on the topic of how scientists reached, or failed to reach, agreement on his theories. Bohr pessimistically recalled in his essay how "it has been difficult to reach mutual understanding not only between philosophers and physicists but even between physicists of different schools." 116

The question of what kind of reality should be given to the times marked by the two clocks once again resurfaced. Arthur O. Lovejoy, who would become famous for founding the history of ideas movement, disagreed with Einstein's interpretation of the differing time assessments by the twins in relativity, siding with Bergson. The two times should not be given the significance that Einstein gave to them: "the fact that two observers disagree concerning the simultaneity of a pair of distant events $[\ldots]$ is no more significant than would be a disagreement between two illiterate persons over the question of whether a whale is a fish." He considered the differences in times described in relativity theory not as referring to real temporal differences but simply as differences arising from disagreements over terminology. One of the persons could mean by “'fish' any free-swimming animal that lives in the water" while for the other one it could mean "gill-breathing and cold-blooded animals." 117

The philosopher Andrew Paul Ushenko, author of the Philosophy of Relativity and Professor at Princeton University, tried to bring some clarity into these debates, noticing that philosophers and even scientists were still reading too much into the differences between the two clock times. He traced the problem to one of Einstein's popular examples of relativity theory, which illustrated time dilation in terms of the time of one person on an embankment and another travelling on a train. Ushenko offered to 
undertake a "slight modification of Einstein's example" in order to "remove the cause of misunderstanding by philosophers." 118 It would be better to talk about "two trains" instead of using the romantic illustration where one person remained on a railroad embankment while the other took off on the train. Two trains would "serve better the purpose of illustrating the parity of alternative reference systems because of a common experience." Denuding the differences amongst the observers in Einstein's examples, he argued, was necessary to properly understand Einstein's theories. Otherwise, precisely the issues of negotiating these differences would come back to haunt him and his science.

In another important essay, the Harvard physicist Percy Bridgman once again argued that the philosophical problem of reaching agreement about matters of time had not disappeared. He insisted that for Einstein's theory to hold, the two famous observers of the twin paradox still had to come to an agreement about their differences and its meaning. They had to be "similar" in some sense and they had to be able to "communicate." Bridgman pointed out the difficulties: "Even the inhabitants of this planet with different cultural backgrounds do not find it always easy to communicate." 119 Why would it be different for the "twins" in the famous paradox?

To understand some of the most metaphysical of questions-the nature of time-some of Einstein's interlocutors brought us down to the most infraphysical of scenarios: two imaginary individuals who disagreed about the meaning of very simple observations. These scenarios were illustrated in various ways. Bridgman referred to "inhabitants of this planet with different cultural backgrounds"; Lovejoy wrote about "disagreement between two illiterate persons over the question of whether a whale is a fish"; Brunschvicg wrote about an observer who "would want to dominate the diverse groups of observers"; Bergson used the most common of names, which were also the holiest: Peter and Paul. ${ }^{120}$

What if living observers were completely eliminated? Would that solve the debate? Langevin boldly stated that "We are ourselves clocks," defending the astounding conclusion that the slow clocks meant slow time, biologically and physically. ${ }^{121}$ But some critics thought that defining time in terms of clocks was "a scientific monstrosity." 122 Clocks frequently ran late, and this did not mean that time was slowing down. Bergson considered the case where the comparison of times could be completely automated, and where the differences between the clock times would be automatically recorded. Under these conditions, he was ready to concede to Einstein: "one could naturally say that [clocks travelling at different speeds] cannot run in synchronicity [ . . ] in effect Time slows down when speed increases." But as soon as conscious beings were reintroduced, Bergson felt justified to continue to claim that the times described by Einstein were not all equally real. "But what is this time that slows down? What are these clocks that are not in synchronicity?" They were, according to him, always "fictional" and "represented." The question of completely eliminating observers and seeing 


\section{Jimena Canales}

how this elimination would affect current views of the universe, Bergson knew well, would be equivalent to opening Pandora's box.

Simple examples invoked complicated questions: would our view of the universe remain valid even if all living observers were eliminated from it? Could observation be completely automated? How was agreement possible? How did consensus depend on communication? How did differences in experience affect consensus? What is parity and what is congruence? The examples used by scientists quickly escaped from the strict categories of either science or politics. "All the tales of passing trains which signal an observer standing in a station, of aviators who smoke cigars in lengthened or contracted periods of time-to what purpose are they?-or, more precisely, for whom are they designed?" asked the philosopher Gaston Bachelard. ${ }^{123}$ Lessons about science or politics could not be simply read out from these "tales."

Finally, what is neutral? "Neutrality, of course may mean several things," answered Ushenko, one of Einstein's interlocutors, arguing in the same text for a "slight modification of Einstein's example" to "serve better the purpose of illustrating the parity of alternative reference systems." Examples aimed to illustrate this "parity" proliferated before and after Ushenko wrote these lines (the train and the embankment, two trains on parallel tracks, an earth-bound observer and a voyager, Peter and Paul, two twins, and perhaps a third triplet). Failing in all senses to be neutral, these attempts remained at the same time both too literal and too literary.

Ushenko, remaining anxious about the "abundance of allegories and metaphors" in the work of physicists, asked if "physics is neutral with regard to philosophy" concluding that "science must rely on [ . . . ] extrascientific considerations", which "proves that science is biased in favor of, and not neutral, with regard to, the latter." ${ }^{124}$ Could there be neutrality between physics and philosophy, between science and extra-science, between science and a theory of knowledge? Yes and no. Scientists and philosophers took sides. But, by no longer fearing the "abundance of allegories and metaphors" in scientific writing, we can see that the problem of neutrality across fields (politics, science, ethics) lay in the boundaries of these fields themselves.

\section{NOTES}

1. I would like to thank Gerald Holton, Al Martinez, Sam Schweber, John Stachel, Richard Staley, and Matthew Stanley for their help and suggestions. Robert K. Merton, "Science and the Social Order", Philosophy of Science 5 (3) (1938), 321-337.

2. The term "view from nowhere" is from Thomas Nagel. The term "situated knowledges" refers to the work of Donna Haraway.

3. Robert Proctor, Value-Free Science?: Purity and Power in Modern Knowledge (Cambridge, MA: Harvard University Press, 1991). 
4. For "precision", see: M. Norton Wise (ed.), The Values of Precision (Princeton: Princeton University Press, 1995). For "objectivity" see Lorraine Daston and Peter Galison, Objectivity (New York: Zone Books, 2007). For "impersonality" see Jimena Canales, A Tenth of a Second: A History (Chicago: Chicago University Press, 2009).

5. For a caution against facile readings of politics from technology see Ken Alder, Engineering the Revolution: Arms and Enlightenment in France, 1763-1815 (Princeton: Princeton University, 1997), 293. For the claim that political philosophy cannot be simply "read out of science" see Peter Galison, "Judgment Against Objectivity", in Caroline A. Jones and Peter Galison (eds.), Picturing Science, Producing Art (New York: Routledge, 1998), 355. For a warning against the uncritical extension of the cultural implications of scientific theories see Gerald Holton, "Einstein's Influence on the Culture of Our Time", in Gerald Holton, Einstein, History and Other Passions (Cambridge, MA: Harvard University Press, 1996).

6. Albert Einstein, "Autobiographical Notes", in Paul Arthur Schilpp (ed.), Albert Einstein: Philosopher-Scientist (La Salle, IL: Open Court, 1949). Citing Emil Fischer.

7. Daston and Galison, Objectivity, 293.

8. By focusing on the literality and literary aspects of this example, this essay goes beyond the "interchange" and its "cultural contexts" model characterizing most work on literature and science, such as Gillian Beer, "Science and Literature", in R.C. Olby, et al. (eds.), Companion to the History of Modern Science (London: Routledge, 1990), 783-798.

9. Peter Galison, Einstein's Clocks, Poincaré's Maps: Empires of Time (New York: W.W. Norton and Company, 2003), 150.

10. "Quotations: International Scientific Organization", Science 53 (15 April 1921), 364-367. The essay contains a quotation from the London Times and a commentary.

11. Cited in Matthew Stanley, "An Expedition to Heal the Wounds of War: 1919 Eclipse and Eddington as Quaker Adventurer", Isis 94 (2003), 58.

12. Robert W. Lawson cited in Otto Nathan and Heinz Norden (eds.), Einstein on Peace (New York: Avenel, 1960), 27-29.

13. Robert W. Lawson cited in ibid.

14. "Einstein and relativity became a focal point through which Eddington could advance both science and international understanding. In practice, these two goals blurred together, as he truly felt that astronomy could not progress in a world wracked by hatred and war." Stanley, "An Expedition to Heal the Wounds of War", 58.

15. Albert Einstein, "How I Became a Zionist", Jüdische Rundschau (1921). This article was not written by Einstein, but was written from an interview approved by him.

16. Albert Einstein, “Time, Space and Gravitation”, The Times, 28 November 1919.

17. Willem H. Julius to Einstein, [Utrecht], 8 May 1920.

18. "Although investigation of the influence of the solar gravitational field on rays of light is purely an objective matter, I am none the less very glad to express my personal thanks to my English colleagues in this branch of science". Einstein, "Time, Space and Gravitation".

19. Einstein, "On the Contribution of Intellectuals to International Reconciliation", written after 29 September 1920.

20. Albert Einstein, "On Internationalism", New York Evening Post, 26 March 1921.

21. 


\section{Jimena Canales}

22.

23. For criticisms of Einstein in Germany in the 1920s, see Milena Wazeck, Einsteins Gegner: die öffentliche Kontroverse um die Relativitätstheorie in den 1920er Jahren (Frankfurt and New York: Campus Verlag, 2009).

24. Einstein's position at this moment with respect to the adoption of his theories, and with respect to the adoption of scientific hypothesis in general, was uncharacteristic. On many other occasions and in different contexts, he expressed a view that a theory choice was often factually underdetermined.

25. Albert Einstein, New York Tribune, 3 April 1921.

26. For Einstein on politics two classic works are Nathan and Norden, eds., Einstein on Peace, 27-29; David E. Rowe and Robert Schulmann (eds.), Einstein on Politics: His Private Thoughts and Public Stands on Nationalism, Zionism, War, Peace and the Bomb (Princeton: Princeton University Press, 2007). For the early period see Thomas Levenson, Einstein in Berlin (New York: Bantam 2003) and for the later one, Fred Jerome, The Einstein File: J. Edgar Hoover's Secret War Against the World's Most Famous Scientist (New York: St. Martin's Press, 2002); Fred Jerome and Rodger Taylor, Einstein on Race and Racism (New Brunswick, NJ: Rutgers University Press, 2005).

27. The paradox was described by Paul Langevin in the Bologna Congress in 1911. Paul Langevin, "L'evolution de l'espace et du temps", Scientia 10 (1911), 31-54.

28. J.C. Hafele and Richard E. Keating, "Around-the-World Atomic Clocks: Predicted Relativistic Gains", Science 177 (1972), 166-168.

29. Albert Einstein, "Relativitätstheorie", Vierteljahresschrift Naturforschende Gesellschaft Zürich 56 (1911), 1-14.

30. Michel Paty, Einstein philosophe: La physique comme practique philosophique, Paul-Laurent Assoun (ed.), Philosophie d'aujourd'hui (Paris: Presses Universitaires de France, 1993), 159.

31. Henri Poincaré, "La théorie de Lorentz et le principe de réaction", in Paul Appell and Gaston Darboux (eds.), Oeuvres (Paris: Gauthier-Villars, (1900) 1954).

32. Albert Einstein, "Bestimmung des Verhältniss der transversalen und longitudinalen Masse des Elektrons”, (1906): 586. Cited in Richard Staley, Einstein's Generation: The Origins of the Relativity Revolution (Chicago: University of Chicago Press, 2008), 308.

33. Albert Einstein, "Relativitätsprinzip" (1907).

34. Cited in Staley, Einstein's Generation: The Origins of the Relativity Revolution, 311.

35. Albert Einstein, The Principle of Relativity (Methuen and Company, Ltd, 1923). n.7

36. Einstein, "Relativitätsprinzip."

37. Hendrik A. Lorentz, The Theory of Electrons (New York: Dover, 1952 [1909]), 230.

38. Gerald Holton, "On the Origins of the Special Theory of Relativity", in Thematic Origins of Scientific Thought (Cambridge, MA: Harvard University Press, 1973), 200.

39. Staley, Einstein's Generation: The Origins of the Relativity Revolution, 329.

40. Albert Einstein, "Die Relativitätstheorie”, in Emil Warburg (ed.), Die Kultur der Gegenwart. Ihre Entwicklung und ibre Ziele (Leipzig: Teubner, 1915). This text was written before 21 October 1913.

41. Lorentz to Einstein, Haarlem, between 1 and 23 January 1915.

42. Ibid.

43. Lorentz to Einstein, Haarlem, 6 June 1916. 
44. Hendrik A. Lorentz, The Einstein Theory of Relativity: A Concise Statement (1919; New York: Brentano's, 1920), 62. Lorentz commented on Einstein's denial of the existence of the ether (another point of disagreement amongst them), but cautioned: "in my opinion it is not impossible that in the future this road [research on the ether], indeed abandoned at present, will once more be followed with good results". Lorentz, The Einstein Theory of Relativity: A Concise Statement, 61-62.

45. Hendrik A. Lorentz, "The Principle of Relativity of Uniform Translation", in A.D. Fokker (ed.), Lectures on Theoretical Physics (1922; London: 1931). Cited in Holton, "On the Origins of the Special Theory of Relativity", 200.

46. German Ambassador in Paris, Report to the Foreign Ministry. Cited in Siegfried Grundmann, Einsteins Akte (Berlin: Springer-Verlag, 1998), 212. The meeting was recounted in the Bulletin de la Société française de Philosophie, 22 (3) (July 1922), 102-113. It was reprinted in Écrits et Paroles, Vol. 3, 497, and in Henri Bergson, "Discussion avec Einstein", in Mélanges (Paris: Presses Universitaires de France, 1972).

47. Cited in Walter Arnold Kaufmann, From Shakespeare to Existentialism: Studies in Poetry, Religion, and Philosophy (Boston: Beacon Press, 1959), 326.

48. Charles Nordmann, Notre maître le temps, Le Roman de la science (Paris: Hachette, 1924), 6.

49. On this topic see Michel Biezunski, Einstein à Paris: le temps n'est plus ... (Vincennes: Presses Universitaires de Vincennes, 1991).

50. Johannes Stark, Deutsche Tageszeitung, 4 April 1922. Cited in Rowe and Schulmann (eds.), Einstein on Politics: His Private Thoughts and Public Stands on Nationalism, Zionism, War, Peace and the Bomb, 13-14.

51. Langevin, cited in Einstein to the Prussian Academy of Sciences, 13 March 1922.

52. For Rathenau's science fiction writings see Frederich Kittler.

53. For Einstein's decision to go to Paris see Nathan and Norden (eds.), Einstein on Peace, 42-54.

54. Nordmann, Notre maître le temps, 160.

55. Ibid., 161.

56. Ibid.

57. Alan D. Sokal and J. Bricmont, Impostures intellectuelles (Paris: O. Jacob, 1997), 176.

58. Thomas Hanna, "Introduction", in Thomas Hanna (ed.), The Bergsonian Heritage (New York: Columbia University Press, 1962), 23.

59. Appendix III in Durée et Simultanéité, Henri Bergson, Mélanges (Paris: Presses Universitaires de France, 1972), 238.

60. Henri Bergson, "Les Temps fictifs et les temps reél", in Mélanges (Paris: Presses Universitaires de France, 1972), 1444.

61. André Lalande, "Philosophy in France, 1922-1923", The Philosophical Review 33 (6) (1924), 543.

62. Rose-Marie Mossé-Bastide, Bergson éducateur (Paris: Presses Universitaires de France, 1955), 126.

63. G. Fontené, La Relativité restreinte (Vuibert, 1922), 132.

64. Intervention of Brunschvicg in Paul Langevin, "Le temps, l'espace et la causalité dans la physique moderne", Bulletin de la Société française de philosophie 12 (1912).

65. Arthur Eddington, The Nature of the Physical World, Ernest Rhys (ed.), Everyman's Library: Science (1928; London: J.M. Dent \& Sons Ltd., 1935), 135.

66. Ibid., 69. 
67. Bergson cited in Jean-Jacques Renoliet, L'UNESCO oubliée: La Société des Nations et la coopération intellectuelle (1919-1946) (Paris: Publications de la Sorbonne, 1999), 31.

68. Germany joined in 1926 after Locarno (1925).

69. For the banning of the Germans from various international unions after the war see Daniel J. Kevles, “'Into Hostile Political Camps': The Reorganization of International Science in World War I", Isis 62 (1971). In 1926 the International Research Council decided to stop the exclusion and invited German scientists to join as members. The Germans, however, declined.

70. This incident is described in Bergson, Mélanges, 1104. And in the Introduction to Angelo Genovesi, "Henry Bergson: Lettere a Einstein", Filosofia 49 (1) (1998): 12 n. 2.

71. Cited in Philipp Frank, Einstein: His Life and Times (New York: Alfred Knopf, 1947), 197.

72. Einstein was "named by the Commission, as everyone else, without having asked for it." Commission Internationale de Coopération Intellectuelle, in Mélanges (Paris: Presses Universitaires de France, 1924). On Einstein's vacillations about his membership see Nathan and Norden (eds.), Einstein on Peace, 59. This is from an original letter in the Algemeen Rijksarchief in the Hague, Holland.

73. Cited in Renoliet, L'UNESCO oubliée: La Société des Nations et la coopération intellectuelle (1919-1946), 27.

74. Commission Internationale de Coopération Intellectuelle, in Mélanges (Paris: Presses Universitaires de France, 1922), 1353.

75. Albert Einstein, "Die Friedens-Warte”, (June 1923), 23.

76. See Max Born on Einstein's resignation in the Born-Einstein correspondence.

77. Born to Einstein, Göttingen, 7 April 1923, in The Born-Einstein Letters: Friendship, Politics and Physics in Uncertain Times (New York: Macmillan, 2005).

78. Einstein to Solovine, Pentecost 1923 (20 May 1923) in Albert Einstein, Letters to Solovine (New York: Philosophical Library, 1987), 58-59: 59. The original reads: "Bergson hat in seinem Buch über Rel. Theorie schwere Böcke geschossen;" The last sentence of the letter is cited as "God forgive him" in Abraham Pais, Einstein Lived Here (Oxford: Clarendon Press, 1994), 75.

79. Einstein to Marie Curie, 25 December 1923. The letter appears in Carl Seelig, ed. Albert Einstein: eine dokumentarische Biographie (Zürich: Europa Verlag,1954), 210. It is also cited in Nathan and Norden (eds.), Einstein on Peace, 64-65.

80. Einstein to Marie Curie, 25 December 1923.

81. Einstein to Besso, [Berlin], 5 January 1924.

82. Mossé-Bastide, Bergson éducateur, 123.

83. Ibid., 125.

84. Documents on Einstein's reacceptance are located in Ministère des Affaires étrangères, Société des Nations: Section des Bureaux internationaux et de la Coopération intellectuelle du Secrétariat de Genève, UNESCO: Correspondence de l'IICI 1837 (Correspondence 30 May-17 June 1924)/SDN, R 1029 (Correspondence 16 April-16 June 1924)/UNESCO, CICI, CICI. 106, b. 568. See Renoliet, L'UNESCO oubliée: La Société des Nations et la coopération intellectuelle (1919-1946), 37 n. 79.

85. Isaac Benrubi, Souvenirs sur Henri Bergson (Neuchâtel: Delachaux \& Niestlé, 1942).

86. Ibid., 107-08. Cited in the Introduction of Genovesi, "Henry Bergson: Lettere a Einstein", 8-9. And in Mossé-Bastide, Bergson éducateur, 126. 
87. "Es wird Gras darüber wachsen, und dann wird man mit mehr Objectivität darüber urteilen." Cited in Benrubi, Souvenirs sur Henri Bergson, 108. Also in Mossé-Bastide, Bergson éducateur, 126.

88. Albert Einstein, "Report on Meeting of the Committee on Intellectual Cooperation”, Frankfurter Zeitung, 29 August 1924.

89. EA 28-037. Otto Nathan and Heinz Norden, Einstein on Peace (New York: Avenel Books, 1960), 77-78.

90. Bergson to H. A. Lorentz, 28 November 1924, in Henri Bergson, Correspondances, André Robinet (ed.) (Paris: Presses Universitaires de France, 2002), 1126.

91. Mossé-Bastide, Bergson éducateur, 145.

92. Bergson to Einstein, 5 February 1925, No. 342600, Box 14, Einstein Archives.

93. Renoliet, L'UNESCO oubliée: La Société des Nations et la coopération intellectuelle (1919-1946), 72.

94. Einstein to Besso, Geneva, 28 July 1925.

95. The first quote is from Albert Einstein, Berliner Tageblatt (1927); the second and third from "Interview", Neue Züricher Zeitung, 20 November 1927.

96. Hendrik Lorentz, "Report", The Astrophysical Journal 68 (5) (1928), 350.

97. Ibid.

98. Ibid., 349 .

99. Ibid., 351.

100. Ibid., 349. Lorentz died that year and Einstein traveled to Holland to give a generous funeral speech.

101. Nathan and Norden, Einstein on Peace, 98.

102. Einstein to Jacques Hadamard, 24 September 1929.

103. Albert Einstein, New York Times, 22 December 1930.

104. Renoliet, L'UNESCO oubliée: La Société des Nations et la coopération intellectuelle (1919-1946), 93.

105. Einstein to Painlevé, 9 April 1930.

106. Einstein to Painlevé, 9 April 1930.

107. Murray to Einstein, Document No. 34 892, 21 June 1932, on p. 2 of 2, Einstein Archives.

108. Cited in Niels Bohr, "Discussion with Einstein on Epistemological Problems in Atomic Physics", in Paul Arthur Schilpp (ed.), Albert Einstein: Philosopher-Scientist, ed. (La Salle, IL: Open Court, 1949), 224

109. Ibid., 228.

110. Ibid., 224

111. André Rousseaux, "De Bergson a Louis de Broglie", in Albert Béguin and Pierre Thévenaz (eds.), Henri Bergson: Essais et témoingnages inédits (Neuchatel: 1941), 280.

112. For the Warsaw Conference of 1938 see S.S. Schweber, QED and the Men Who Made It : Dyson, Feynman, Schwinger, and Tomonaga, Princeton series in physics (Princeton: Princeton University Press, 1994), 93-104.

113. Bohr, "Discussion with Einstein on Epistemological Problems in Atomic Physics", 236.

114. Renoliet, L'UNESCO oubliée: La Société des Nations et la coopération intellectuelle (1919-1946), 7.

115. Albert Einstein, “A Re-examination of Pacifism”, Polity 3 (1) (January 1935), 4-5.

116. Bohr, "Discussion with Einstein on Epistemological Problems in Atomic Physics".

117. Arthur O. Lovejoy, "The Dialectical Argument against Absolute Simultaneity. II", The Journal of Philosophy 27 (24) (20 November 1930), 651-652. 
118. Paul Andrew Ushenko, "Einstein's Influence on Contemporary Philosophy", in Paul Arthur Schilpp (ed.), Albert Einstein: Philosopher-Scientist (La Salle, IL: Open Court, 1949), 619, 607-645.

119. Percy W. Bridgman, Einstein's Theories and the Operational Point of View, ed. Paul Arthur Schilpp, Vol. 7, The Library of Living Philosophers (La Salle, IL: Open Court, 1949), 342.

120. Intervention of Brunschvicg in Langevin, "Le temps, l'espace et la causalité dans la physique moderne".

121. Ibid.

122. Lucien Fabre cited in André Metz, "Le Temps d'Einstein et la philosophie: à propos de l'ouvrage de M. Bergson, Durée et simultanéité", Revue de philosophie 31 (1924), 66.

123. Gaston Bachelard, "The Philosophic Dialectic of the Concepts of Relativity", in Paul Arthur Schilpp (ed.), The Library of Living Philosophers (La Salle, IL: Open Court, 1949), 572.

124. Ushenko, "Einstein's Influence on Contemporary Philosophy”, 612, 13, 19. 